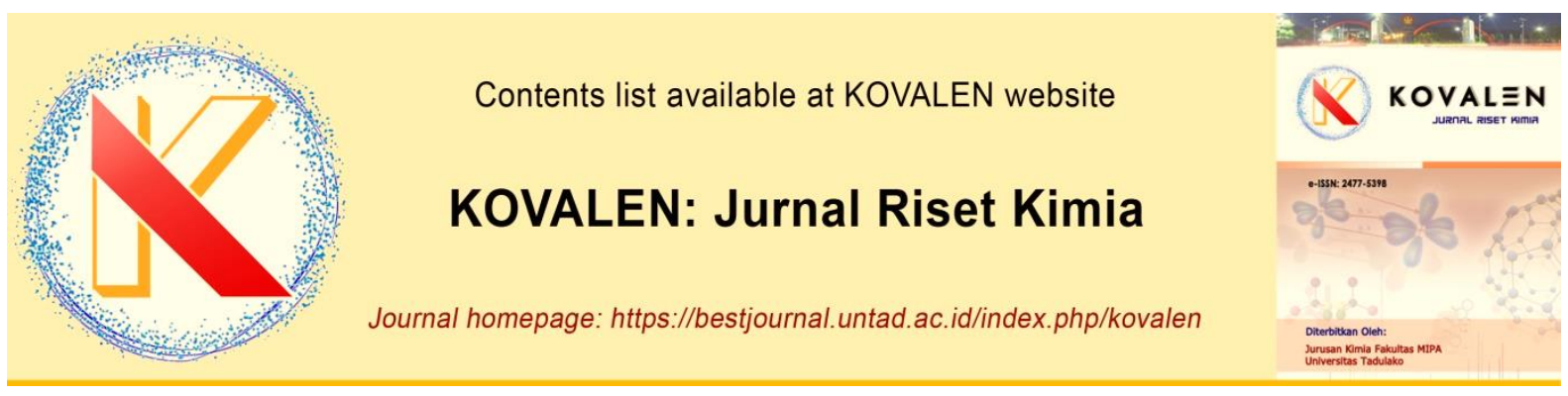

\title{
Pengaruh Variasi Konsentrasi NaOH Terhadap Nilai Derajat Deasetilasi Kitosan dari Limbah Cangkang Kerang Hijau (Perna viridis $L$ )
}

\section{[The Effect of $\mathrm{NaOH}$ Concentration on The Value of The Deacetylation Degree of Chitosan from Green Mussels Shell Waste (Perna viridis L)]}

\author{
Winda Trisna Wulandari, Nurzaman, Anindita Tri Kusuma Pratita, Keni Idacahyati \\ Program Studi S1 Farmasi, Sekolah Tinggi IImu Kesehatan Bakti Tunas Husada Tasikmalaya, Jalan Cilolohan \\ No 36, Jawa Barat, Indonesia. \\ *Corresponding author: windatrisna@stikes-bth.ac.id
}

\begin{abstract}
Chitin which is the result of processing from green conch shell waste can be transformed into chitosan through a deacetylation process using variations in the concentration of $\mathrm{NaOH}$. This study aims to determine the optimum conditions of variations in base concentration to the value of the degree of deacetylation of chitosan. The types of bases used are $\mathrm{NaOH}$ with the concentration variations of $50 \%, 55 \%$, and $60 \%$. Chitosan obtained was calculated the yield and characterized using FTIR. The results showed the optimum condition of the value of chitosan deacetylation degree was achieved by using $60 \% \mathrm{NaOH}$ which produced the highest deacetylation degree value of $76.5 \%$.
\end{abstract}

Keywords: Green mussels shell, chitin, chitosan, deacetylation

ABSTRAK. Kitin hasil pengolahan dari limbah cangkag kerang hijau dapat ditranformasikan menjadi kitosan melalui proses deasetilasi menggunakan variasi konsentrasi $\mathrm{NaOH}$. Penelitian ini bertujuan untuk mengetahui kondisi optimum dari variasi konsentrasi basa terhadap nilai derajat deasetilasi kitosan. Jenis basa yang digunakan adalah $\mathrm{NaOH}$ dengan variasi konsentrasi yaitu $50 \%, 55 \%$ dan $60 \%$. Kitosan yang diperoleh dihitung rendemenya dan dikarakterisasi menggunakan FTIR. Hasil penelitian menunjukan kondisi optimum nilai derajat deasetilasi kitosan dicapai dengan menggunakan $\mathrm{NaOH} 60 \%$ yang menghasilkan nilai derajat deasetilasi tertinggi yaitu sebesar $76,5 \%$.

Kata kunci: Cangkang kerang hijau, kitin, kitosan, deasetilasi

Riwayat artikel: Diterima 8 September 2020, Disetujui 2 November 2020

Cara sitasi: Wulandari, W T., Nurzaman., Pratita A T K., \& Idacahyati, K. (2020). Pengaruh Variasi Konsentrasi NaOH Terhadap Nilai Derajat Deasetilasi Kitosan Dari Limbah Cangkang Kerang Hijau (Perna viridis L). KOVALEN: Jurnal Riset Kimia, 6(3): 171176.

DOI: https://doi.org/10.22487/kovalen.2020.v6.i3.15277

\section{LATAR BELAKANG}

Kerang hijau merupakan salah satu jenis kerang yang sering dikonsumsi oleh masyarakat, Kerang jenis ini bukan hanya disajikan di tempat makan seafood tapi akhirakhir ini kerang hijau juga sering dijual dengan menggunakan roda dipinggir jalan. Hal ini menunjukkan bahwa tingkat konsumsi 
masyarakat terhadap kerang hijau semakin meningkat. Akan tetapi limbah cangkang kerang hijau belum dimanfaatkan secara optimal di masyarakat dan hanya menjadi limbah. Padahal cangkang kerang hijau ini memiliki kandungan kitin yang dapat diolah menjadi kitosan yang sangat bermanfaat pada berbagai bidang baik bidang kesehatan, pangan, lingkungan, tekstil, kosmetik, dII (Wulandari et al., 2020).

Kitosan merupakan polisakarida yang terdiri dari D-glukosamin dan N-asetil-Dglukosamin yang terhubung melalui ikatan $\beta$ $(1,4)$. Kitosan memiliki sifat biologis yang sangat baik diantaranya adalah biokompatibel, biodegradable, non-toksik, antioksidan, dll (Huang et al., 2020).

Kitosan berasal dari senyawa kitin yang dihasilkan dari proses deasetilasi. Transformasi kitin menjadi kitosan disebut tahap deasetilasi, yaitu dengan penambahan basa pada konsentrasi tinggi. Reaksi deasetilasi dengan menggunakan alkali pada suhu tinggi akan menyebabkan terlepasnya gugus asetil ($\mathrm{COCH}_{3}$ ) dari molekul kitin dan membentuk gugus amina bebas $\left(-\mathrm{NH}_{2}\right)$ yang merupakan ciri bahwa molekul kitosan sudah terbentuk (Victor et al., 2016).

Hasil penelitian Moura et al. (2011) menunjukkan bahwa derajat deasetilasi dari kitosan mempengaruhi biofilm yang dihasilkan. Kitosan dengan derajat deasetilasi lebih tinggi memiliki water vapor permeability, tensile strength dan elongasi yang lebih baik dibandingkan dengan kitosan yang memiliki derajat deasetilasi yang rendah (Moura et al., 2011). Oleh karena itu, dibutuhkan bahan dasar kitosan dengan nilai derajat deasetilasi yang tinggi agar dapat diaplikasikan pada berbagai bidang.
Terdapat beberapa faktor yang dapat mempengaruhi nilai derajat deasetilasi dari kitosan salah satunya adalah konsentrasi basa kuat yang digunakan. Hal ini sesuai dengan penelitian dari Azhar et al. (2010) yang menunjukkan bahwa kitosan dari limbah kulit udang memiliki nilai derajat deasetilasi sebesar $57,318 \%$ dan $65,636 \%$ berturut-turut untuk penambahan $\mathrm{NaOH} 40$ dan $50 \%$. Hal yang sama juga diperoleh pada nilai derajat deasetilasi kitosan dari cangkang kerang kampak yang menunjukkan nilai derajat deasetilasi tertinggi pada penambahan $\mathrm{NaOH}$ $60 \%$ dibandingkan dengan 50 dan $55 \%$ yaitu sebesar $72,42 \pm 1,23$ pada suhu $100^{\circ} \mathrm{C}$ (Citrowati et al., 2019).

Sampai saat ini pengaruh konsentrasi $\mathrm{NaOH}$ terhadap nilai derajat deasetilasi kitosan dari limbah cangkang kerang hijau masih belum dilakukan, oleh karena itu penelitian ini bertujuan untuk mengetahui pengaruh konsentrasi $\mathrm{NaOH}$ terhadap nilai derajat deasetilasi kitosan dari limbah cangkang kerang hijau (Perna virdis L). Variasi konsentrasi $\mathrm{NaOH}$ yang digunakan pada penelitian ini adalah 50,55 , dan $60 \%$.

\section{METODE PENELITIAN}

\section{Bahan dan Peralatan}

Bahan yang digunakan dalam penelitian ini adalah limbah cangkang kerang hijau (perna viridis L), Natrium Hidroksida $(\mathrm{NaOH})$, (Bratachem $\left.{ }^{\circledR}\right), \quad$ Asam Klorida $(\mathrm{HCl})$ (Bratachem $\left.{ }^{\circledR}\right)$, Asam Asetat $\left(\mathrm{CH}_{3} \mathrm{COOH}\right)$ (Bratachem®), Aqua DM.

Alat yang digunakan pada penelitian ini adalah ayakan mesh 60 , alat gelas (pyrex®), kertas saring, magnetik stirrer (MS20®), oven (Memmert@), neraca analitik (Mettler Toledo; AL-204 Analitycal Balance®), pH indikator 
universal, spektrofotometer Fourier Transform Infrared (FTIR) Simadzu, hot plate.

\section{Prosedur Penelitian}

\section{Preparasi limbah cangkang kerang hijau}

Cangkang kerang hijau (Perna viridis $\mathrm{L}$ ) dibersihkan dengan air mengalir sampai bersih dan dikeringkan dibawah sinar matahari. Cangkang yang telah kering kemudian dihaluskan untuk mendapatkan serbuk cangkang kerang hijau dengan ukuran 60 mesh.

\section{Deproteinasi}

Sampel yang telah dihaluskan dimasukkan kedalam gelas kimia $500 \mathrm{~mL}$, kemudian ditambahkan larutan $\mathrm{NaOH} 3 \%$ dengan perbandingan $3: 1 \quad(\mathrm{~mL} \quad \mathrm{NaOH} / \mathrm{g}$ cangkang) dan dilakukan pengadukan dengan magnetic stirrer selama 1 jam. Setelah itu dilakukan pemanasan dengan hot plate pada suhu $80^{\circ} \mathrm{C}$ selama 30 menit. Larutan disaring dan dinetralkan hingga $\mathrm{pH} 7$ dengan cara pencucian menggunakan aqua $\mathrm{dm}$. Hasil rendemen proses deproteinasi kemudian dikeringkan dalam oven pada suhu $60^{\circ} \mathrm{C}$ sampai kering (Wulandari et al., 2020).

\section{Demineralisasi}

Serbuk cangkang kerang hijau (Perna viridis $\mathrm{L}$ ) hasil deproteinasi ditambahkan $\mathrm{HCl}$ 1,25 $\mathrm{N}$ dengan perbandingan 3:1 (mL HCl/g cangkang). Kemudian dilakukan pemanasan dengan menggunakan hot plate pada suhu $75^{\circ} \mathrm{C}$ selama 1 jam. Setelah dilakukan pemanasan, larutan disaring dan dinetralkan dengan cara pencucian menggunakan aquadm hingga $\mathrm{pH}$ larutan 7. Residu yang sudah netral tersebut kemudian dikeringkan dalam oven pada suhu $60^{\circ} \mathrm{C}$ sampai kering (Wulandari et al., 2020).

\section{Deasetilasi}

Pembuatan kitosan dilakukan melalui proses deasetilasi kitin dengan metode Knorr yaitu dengan larutan $\mathrm{NaOH}(50 \%, 55 \%, 60 \%)$ perbandingan yang digunakan adalah 20:1 (mL basa/g kitin) kemudian campuran dipanaskan pada suhu $95^{\circ} \mathrm{C}$ sambil diaduk selama 60 menit. Setelah dingin, disaring dan padatan yang diperoleh dinetralkan dengan cara pencucian dengan aqua $\mathrm{dm}$ hingga $\mathrm{pH} 7$. Padatan kemudian dikeringkan dalam oven pada suhu $60^{\circ} \mathrm{C}$ sampai kering.

\section{Karakterisasi FTIR}

Karakterisasi FTIR digunakan untuk menganalisis gugus fungsi dan penentuan derajat deasetilasi dari kitosan yang diperoleh. Sebanyak $1 \mathrm{mg}$ kitosan dicampur dengan $\mathrm{KBr}$ $1 \%(b / b)$, campuran ini kemudian ditekan sehingga berbentuk pelet. Pelet $\mathrm{KBr}$ yang diperoleh dimasukkan ke tempat cuplikan dan direkam spektrum serapan infra merahnya pada bilangan gelombang $4000-400 \mathrm{~cm}$.

\section{Anaisis data}

Kitosan yang telah dihasilkan dari proses deasetilasi kemudian ditimbang dan dicatat beratnya. Rendemen menggunakan persamaan sebagai berikut:

$$
\text { Rendemen kitosan }(\%)=\frac{A}{B} \times 100 \%
$$
Keterangan:

A : massa kitosan kering ( $\mathrm{g})$

$$
\text { B : massa kitin yang diperoleh (g) }
$$

Niai derajat deasetilai kitosan dapat dhitung dengan rumus (Wulandari et al., 2020) sebagai berikut:

$$
\mathrm{DD}=\left(1-\frac{A 1655}{A 3450} X \frac{1}{1,33}\right) X 100 \%
$$

Keterangan:

DD : Derajat deasetilasi.

A1655 : Absorbansi pada bilangan gelombang 1655. Bilangan 
gelombang ini menunjukkan

kandungan ikatan amina

untuk perhitungan

kandungan gugus $\mathrm{N}$-asetil.

A3450

: Absorbansi pada bilangan gelombang 3450. Bilangan gelombang ini menunjukkan ikatan hidroksil sebagai faktor koreksi.

Faktor 1,33 untuk kitosan yang terdeasetilasi sempurna

\section{HASIL DAN PEMBAHASAN}

\section{Pembentukan Kitin dan Kitosan}

Kitin dihasilkan melalui tahapan demineralisasi dan deproteinasi yang ditandai dengan serbuk berwarna putih agak kecoklatan. Kitin yang diperoleh dari limbah cangkang kerang hijau adalah sebanyak $48,06 \%$.

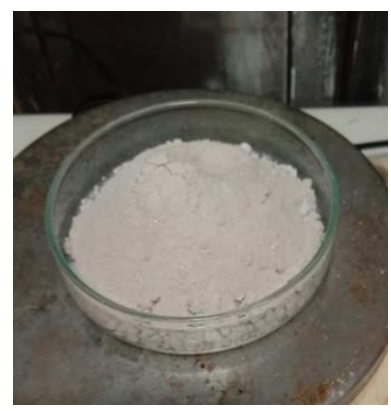

Gambar 1. Kitosan dari limbah cangkang kerang hijau

Kitosan dihasilkan melalui reaksi deasetilasi kitin menggunakan $\mathrm{NaOH}$. Rendemen kitosan yang diperoleh adalah 44,8\%; 15,9\%; dan 31,24\% berturut-turut untuk konsentrasi $\mathrm{NaOH}$ 50, 55, dan 60\%. Kitosan yang dihasilkan berupa serbuk berwarna putih seperti yang terlihat pada Gambar 1. Spektrum FTIR untuk kitin dan kitosan masing-masing ditunjukkan pada Gambar 2 dan 3.

Pada spektrum FTIR kitin maupun kitosan dapat dilihat bahwa terjadi vibrasi pada bilangan gelombang sekitar $3400 \mathrm{~cm}^{-1}$ yang menunjukkan adanya gugus $-\mathrm{OH}$ yang overlapping dengan gugus - NH. Pada spektra IR gugus fungsi $\mathrm{C}=\mathrm{O}$ bilangan gelombang $1784,15 \mathrm{~cm}^{-1}$ (kitin) memiliki pita serapan kuat, yang menandakan adanya gugus amida, dan pada kitosanpun masih terdapat gugus $\mathrm{C}=\mathrm{O}$ pada bilangan gelombang $1788,90 \mathrm{~cm}^{-1}$, hal ini disebabkan oleh tidak sempurnanya proses deasetilasi. Bilangan gelombang $700-800 \mathrm{~cm}^{-1}$ pada spektrum kitosan mengindikasikan adanya vibrasi tekuk $\mathrm{N}-\mathrm{H}$ dari amina $\left(-\mathrm{NH}_{2}\right)$. Bilangan gelombang 1083,08 $\mathrm{cm}^{-1}$ menunjukkan vibrasi ulur dari gugus -C-O (Cakasana et al., 2014).

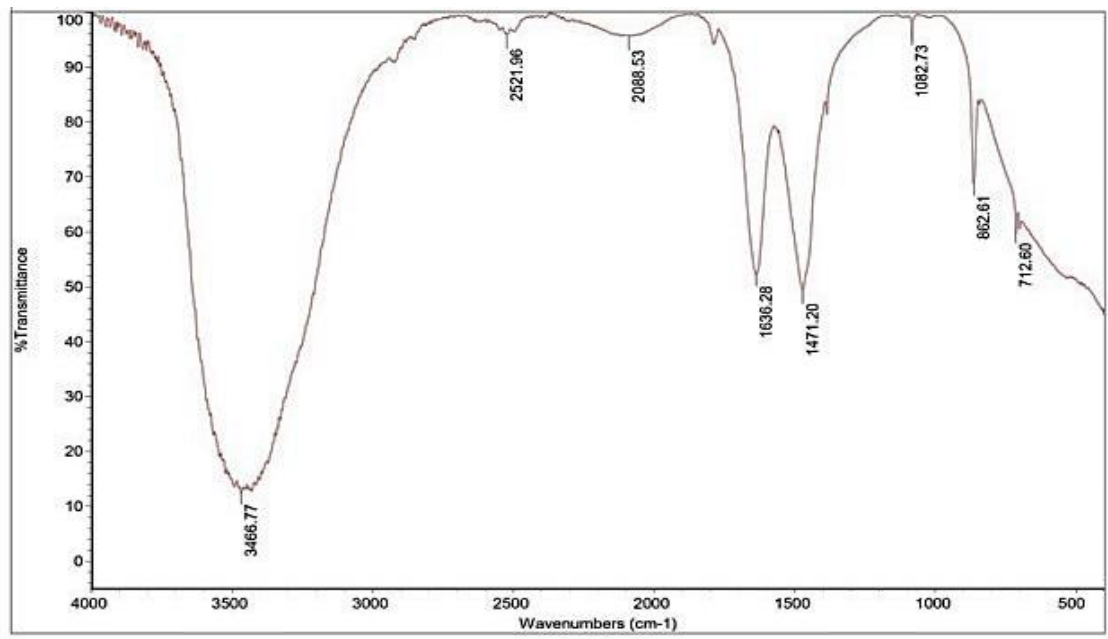

Gambar 2. Spektrum FTIR kitin 


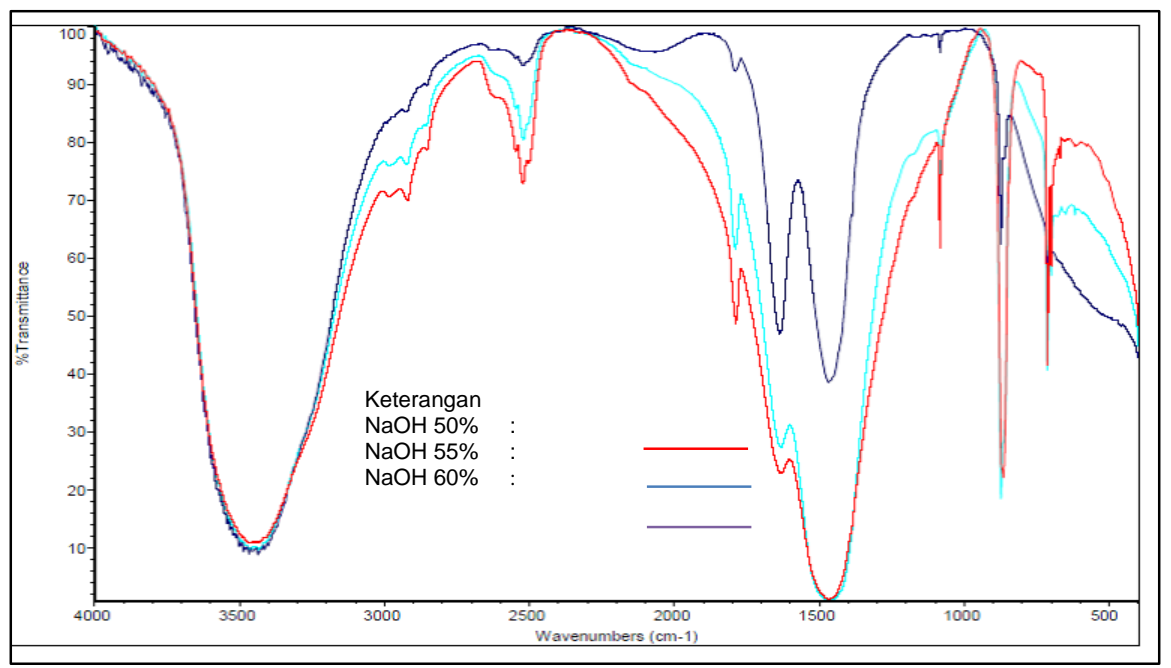

Gambar 3. Spektrum FTIR kitosan

\section{Nilai Derajat Deasetilasi (DD)}

Derajat deasetilasi kitosan dari cangkang kerang hijau (Perna viridis L) dilakukan merupakan suatu parameter yang menujukan presentase gugus asetil yang dapat dihilangkan. Nilai derajat deasetilasi Kitosan cangkang kerang hijau (Perna viridis L) ditunjukkan pada Tabel 1.

Tabel 1. Nilai derajat deasetilasi

\begin{tabular}{cc}
\hline Konsentrasi (NaOH) & Nilai (DD) \\
\hline $50 \%$ & $51 \%$ \\
$55 \%$ & $59 \%$ \\
$60 \%$ & $76,5 \%$ \\
\hline
\end{tabular}

Nilai derajat deasetilasi kitosan dari limbah cangkang kerang hijau pada konsentrasi $\mathrm{NaOH}$ $60 \%$ telah memenuhi standar mutu kitosan dengan nilai derajat deasetilasi $\geq 70 \%$ (Victor et al., 2016) bahkan lebih tinggi apabila dibandingkan dengan kitosan dari sumber lain pada penggunaan konsentrasi $\mathrm{NaOH}$ yang sama diantaranya cangkang kerang kampak yang memiliki nilai Derajat Deasetilasi $72,42 \pm 1,23$ pada suhu $100^{\circ} \mathrm{C}$ dan $73,15 \pm 0,24$ pada suhu $130^{\circ} \mathrm{C}$ (Citrowati et al., 2019), Cangkang Rajungan sebesar 74,85\% (Tobing,
Basid, \& Prasetya, 2011). Akan tetapi lebih rendah apabila dibandingkan dengan kitosan dari limbah kulit udang yaitu sebesar $83,25 \%$ (Dompeipen et al., 2016) dan 84,85\% (Agustina et al., 2015). Hal ini karena limbah cangkang kerang lebih tebal apabila dibandingkan dengan cangkang atau kulit udang sehingga akan lebih sulit ditembus sehingga reaksi deasetilasi pun akan lebih sulit.

Nilai derajat deasetilasi kitosan cangkang kerang hijau yang paling besar adalah pada konsentrasi $\mathrm{NaOH} 60 \%$ yaitu sebesar $76,5 \%$. Hasil penelitian dari Tobing., et al. (2011) mengenai peningkatan derajat deasetilasi dari cangkang rajungan dengan variasi konsentrasi $\mathrm{NaOH}$ 40, 50, 60 dan 70\% menunjukkan bahwa konsentrasi $\mathrm{NaOH}$ terbesar yaitu $70 \%$ menghasilkan nilai derajat deasetilasi tertinggi dengan nilai sebesar 77\% (Tobing et al., 2011). Hasil yang sama juga ditunjukkan pada kitosan dari cangkang udang putih dengan variasi konsentrasi $\mathrm{NaOH}$ dari 30-70\% menunjukkan nilai derajat deasetilasi tertinggi sebesar $87,5 \%$ pada konsentrasi $\mathrm{NaOH} 70 \%$ (Wibowo et al., 2019).

Hal ini juga menunjukkan bahwa semakin tinggi konsentrasi basa maka semakin tinggi 
pula nilai derajat deasetilasi dari kitosan. Konsentrasi $\mathrm{NaOH}$ yang semakin tinggi mengakibatkan semakin banyaknya gugus hidroksil yang dapat menyebabkan terjadinya reaksi adisi pada gugus karbonil kitin sehingga pembentukan amina semakin banyak dan derajat deasetilasi meningkat (Bahri et al., 2015; Mursida et al., 2018). Selain itu, penggunaan $\mathrm{NaOH}$ dengan konsentrasi yang tinggi dapat merubah konformasi kitin yang tebal dan rapat sehingga proses deasetilasi akan semakin mudah terjadi (Tobing et al., 2011).

\section{KESIMPULAN}

Berdasarkan hasil penelitian, semakin tinggi konsentrasi $\mathrm{NaOH}$ maka nilai DD semakin tinggi, pada penelitian ini nilai DD tertinggi dari cangkang kerang hijau ditunjukan oleh konsentrasi $\mathrm{NaOH} 60 \%$, yaitu $76,5 \%$.

\section{DAFTAR PUSTAKA}

Agustina, S., Swantara, I., \& Suartha, I. (2015). Isolasi Kitin, Karakterisasi, dan Sintesis Kitosan dari Kulit Udang. Jurnal Kimia, 9(2): 271-278.

Azhar, M., Efendi, J., Syofyeni, E., Lesi, RM., Novalina, S. (2010). Pengaruh Konsentrasi $\mathrm{NaOH}$ Dan $\mathrm{KOH}$ Terhadap Derajat Deasetilasi Kitin Dari Limbah Kulit Udang. EKSAKTA, 1:1-8.

Bahri, S., Rahim, E. A., Syarifuddin. (2015). Derajat Deasetilasi Kitosan dari Cangkang Kerang Darah Dengan Penambahan Naoh Secara Bertahap. KOVALEN: Jurnal Riset Kimia, 1(1): 3642.

Cakasana, N., Suprijanto, J., \& Sabdono, A. (2014). Aktivitas Antioksidan Kitosan yang Diproduksi dari Cangkang Kerang Simping (Amusium sp) dan Kerang Darah (Anadara sp). Journal of Marine Research. 3(4).

Citrowati, A. N., Satyantini, W. H., \& Mahasri, G. (2019). Pengaruh Kombinasi Naoh Dan Suhu Berbeda Terhadap Nilai Derajat Deasetilasi Kitosan Dari Cangkang Kerang Kampak (Atrina pectinata). Journal of Aquaculture and Fish Health, 6(2): 48. https://doi.org/10.20473/jafh.v6i2.11279

Dompeipen, E. J., Kaimudin, M., Dewa, R. P., Riset, B., Ambon, I., Cengkeh, J. K., \& Ambon, B. M. (2016). Isolasi kitin dan kitosan dari limbah kulit udang, Majalah BIAM, 12(1).

Huang, L., Bi, S., Pang, J., Sun, M., Feng, C., \& Chen, X. (2020). Preparation and characterization of chitosan from crab shell (Portunus trituberculatus) by $\mathrm{NaOH} /$ urea solution freeze-thaw pretreatment procedure. International Journal of Biological Macromolecules, 147: $\quad$ 931-936. https://doi.org/10.1016/j.ijbiomac.2019.10 .059

Moura, C. M. de, Moura, J. M. de, Soares, N. M., \& Pinto, L. A. de A. (2011). Evaluation of molar weight and deacetylation degree of chitosan during chitin deacetylation reaction: Used to produce biofilm. Chemical Engineering and Processing: Process Intensification, 50(4): 351-355. https://doi.org/10.1016/j.cep.2011.03.003

Mursida. T., Tasir., Sahriawati. (2018). Efektifitas Larutan Alkali Pada Proses Deasetilasi dari Berbagai Bahan Baku Kitosan. JPHPI, 21(2): 356-366.

Tobing, M. T. L., Basid, N., \& Prasetya, A. (2011). Peningkatan Derajat Deasetilasi Kitosan dari Cangkang Rajungan. Jurnal Kimia Sains Dan Aplikasi, 14(3): 83-88.

Victor M, S., Andhika, B., \& Syauqiah, I. (2016). Pemanfaatan Kitosan Dari Limbah Cangkang Bekicot (Achatina). Jurnal Konversi, 5(1): 22-26.

Wibowo, P., Bayu, R., Wijoyo, T., \& Rezeki, S. (2019). Pengaruh Konsentrasi $\mathrm{NaOH}$ pada Deasetilasi Kitin dari Cangkang Udang Putih (Litopenaeus vannamei) dan Aktivitasnya pada Air Gambut, 07(1): 3743.

Wulandari, W. T., Puspitasari, R., \& Aprilia, A. Y. (2020). Antioxidant Activity of Chitosan from the Waste of Green Mussels Shell (Perna viridis L), 26: 33-35. https://doi.org/10.2991/ahsr.k.200523.01 0 